Check for updates

The BMJ

Cite this as: $B M J 2020 ; 371: \mathrm{m4666}$ http://dx.doi.org/10.1136/bmj.m4666 Published: 27 November 2020

\section{Ethnic minority doctors are less likely than white colleagues to report workplace improvements during pandemic}

Abi Rimmer

Doctors from ethic minority groups were less likely than white colleagues to experience improved team working and knowledge sharing during the first wave of the covid-19 pandemic, a report by the General Medical Council (GMC) has found.

While most UK doctors reported some positive impacts despite the strain the pandemic has placed on healthcare, positive experiences were not shared equally. Results from the poll of 3693 doctors, carried out in June and July 2020, were published in the GMC's annual State of Medical Education and Practice in the UK report on 27 November. ${ }^{1}$

Although three fifths $(61 \%)$ of white doctors who responded to the survey said that the sharing of knowledge and experiences had been positively affected by the pandemic, just $46 \%$ of ethnic minority doctors felt the same.

The survey also showed that $68 \%$ of white doctors believed that teamwork between doctors had improved during the pandemic, compared with $55 \%$ of ethnic minority doctors. And improvements in the speed of workplace changes were reported by $57 \%$ of white doctors, compared with $38 \%$ of ethnic minority doctors.

\section{Supportive and compassionate leadership}

The GMC's chief executive, Charlie Massey, said it was a concern that ethnic minority doctors were less likely to experience any positive impacts on workplaces than their white colleagues.

"We know BAME [black, Asian, and minority ethnic] doctors too often lack the supportive and compassionate leadership that is required to thrive," he said. "Doctors of all grades, and from all backgrounds, need and deserve the same levels of support if they are to provide the best possible care for patients, in what will continue to be difficult months ahead."

Andrew Goddard, president of the Royal College of Physicians, said that the report's findings echoed work done by his college, which found that doctors from ethnic minority groups had to apply for many more consultant posts than white doctors to secure a job. ${ }^{2}$

"The inequalities highlighted in the report are stark, with BAME doctors struggling far more than their white colleagues," he said. "Our own data shows much the same, with BAME doctors consistently disadvantaged when it comes to getting a job.”

Miriam Deakin, director of policy and strategy at NHS Providers, which represents trusts, said that it was troubling to see that positive impacts on workplaces in the face of the pandemic were not shared to the same degree by ethnic minority doctors.

She said, "This report clearly shows that, within the NHS, there is still much work to do to improve equality and diversity in the workplace, and we must continue to invest in support for this across the health and care system."

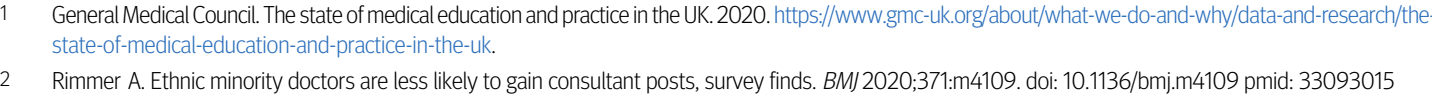

